\title{
Influence of remote ischemic conditioning and tramadol hydrochloride on oxidative stress in kidney ischemia/ reperfusion injury in rats ${ }^{1}$
}

Rita de Cássia Silva de Oliveira', Marcus Vinicius Henriques Brito", Rubens Fernando Gonçalves Ribeiro Júnior'I", Leonam Oliver Durval Oliveira"', Andrew Moraes Monteiro'v, Fernando Mateus Viegas Brandão'v , Lainy Carollyne da Costa Cavalcantev ${ }^{v}$ Eduardo Henrique Herbster Gouveiav, Higor Yuri Bezerra Henriques ${ }^{\vee}$

'PhD, Full Professor, Department of Pharmacology, Universidade Estadual do Pará (UEPA), Belem-PA, Brazil. Conception, design and scientific content of the study; critical revision.

"PhD, Full Professor, Department of Experimental Surgery, UEPA, Belem-PA, Brazil. Conception, design and scientific content of the study; critical revision.

'"Master, Postgraduate Program in Surgery and Experimental Research, UEPA, Belem-PA, Brazil. Statistical analysis, manuscript preparation, English version.

IVGraduate student, School of Medicine, UEPA, Belem-PA, Brazil. Technical procedures, interpretation of data, manuscript preparation.

VGraduate student, School of Medicine, Centro Universitário do Pará (CESUPA), Belem-PA, Brazil. Technical procedures, interpretation of data, manuscript preparation.

Abstract

Purpose: To evaluate the effects of tramadol hydrochloride associated to remote ischemic perconditioning on oxidative stress.

Methods: Twenty five male rats (Wistar) underwent right nephrectomy and were distributed into five groups: Sham group (S); Ischemia/Reperfusion group (I/R) with 30 minutes of renal ischemia; Remote ischemic perconditioning group (Per) with three cycles of 10 minutes of I/R performed during kidney ischemia; Tramadol group $(T)$ treated with tramadol hydrochloride $(40 \mathrm{mg} / \mathrm{kg})$; remote ischemic perconditioning + Tramadol group (Per+T) with both treatments. Oxidative stress was assessed after 24 hours of reperfusion.

Results: Statistical differences were observed in MDA levels between I/R group with all groups $(p<0.01)$, in addition there was difference between Tramadol with Sham, Per and Per+T groups $(p<0.05)$, both in plasma and renal tissue.

Conclusion: Remote ischemic perconditioning was more effective reducing renal ischemiareperfusion injury than administration of tramadol or association of both treatments.

Key words: Tramadol. Ischemia. Reperfusion. Oxidative Stress. Kidney. Rats. 


\section{- Introduction}

Acute renal failure (ARF) is a high incidence syndrome, responsible for a high rate of morbidity and mortality, affecting about $30 \%$ to $50 \%$ of patients in intensive care units ${ }^{1}$. Among the characteristics of the ARF are decreased glomerular filtration rate, tubular necrosis, as well as abrupt increase in serum levels of urea and creatinine 48 hours ${ }^{2}$.

The main cause is related to ischemia and reperfusion syndrome which is related to clinical situations the example of sepsis, shock, low cardiac output, or surgical procedures such as kidney transplants ${ }^{2}$.

This syndrome is initiated from a local or general reduction of renal blood flow, which leads to depletion of intracellular ATP failure of ion pumps with ions entry osmotically active in the cell that result in cell swelling, the matrix and mitochondrial cristae. Furthermore, there is accumulation of substances such as xanthine oxidase, which plays a critical role in reperfusion injury ${ }^{3}$.

Thus, in order to minimize the damage caused by oxidative stress on physiology of the body under ischemia/reperfusion, different therapeutic approaches were used, such as hypothermia ${ }^{4}$, administration of antioxidant substances ${ }^{5,6}$ and hypertonic saline solutions ${ }^{7}$.

There is also the technique of remote ischemic perconditioning, which is held remote ischemic conditioning by a tourniquet applied to the back of the animal member during the time of primary ischemia ${ }^{8}$, which was used with excellence in prevent reperfusion injury in the myocardium ${ }^{9}$. Its protective effect has also been demonstrated on the brain, renal and liver ischemia ${ }^{10}$.

In addition, several studies in the literature have shown that opioid pathway is involved in preservation of tissues during hypoxia, which is mediated through $\mu$-opioid receptor ${ }^{11}$, among them is tramadol hydrochloride. Recent studies reveal the effect of this anesthetic in reducing lipid peroxidation. Furthermore, it was used for the management of myocardial ischemia and the brain tissue ${ }^{12}$.

In view of the protective effects of ischemic conditioning described in the literature and its potential as a therapeutic approach to ischemia/reperfusion, this study aimed to evaluate the effects of tramadol, associated to remote ischemic perconditioning on oxidative stress in renal ischemia/reperfusion.

\section{- Methods}

All experiments were performed in accordance with Brazilian law for scientific use of animals, and this project was formally approved by the local ethics committee for animal experimentation (Protocol 08/2015).

Twenty-five adult male Wistar rats aged 10-12 weeks (250-350g), were obtained from the Evandro Chagas Institute. The rats were maintained with free access to regular food and water, at $22 \pm 1^{\circ} \mathrm{C}$ under a 12 -h light/ dark cycle.

The animals were randomly distributed into five experimental groups, each with five rats: sham group (S) were submitted to all operative procedures, except vessels occlusion. I/R group were undergoing 30-minutes of ischemia and 24 hours of reperfusion. Remote ischemic perconditioning group (Per) were submitted to three cycles of 10 -minutes of $I / R$ with $a$ tourniquet on left hind limb ${ }^{8}$. Tramadol group were received subcutaneous administration of $40 \mathrm{mg} / \mathrm{kg}^{13}$ tramadol hydrochloride after ischemic period. Remote ischemic perconditioning + Tramadol group $(\mathrm{Per}+\mathrm{T})$ received both treatments (Figure 1 ). 


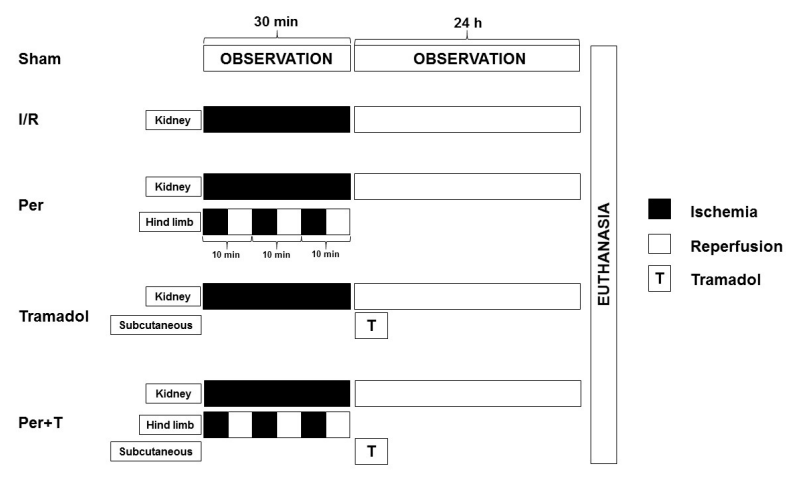

Figure 1 - Procedures between groups.

The rats were fasted overnight before the experiments, but were given free access to water. They were weighed and anesthetized using an intraperitoneal injection of ketamine hydrochloride 10\% and xylazine hydrochloride 2\% (70mg/ $\mathrm{kg}$ and $10 \mathrm{mg} / \mathrm{kg}$, respectively). During the operations, additional doses were administered if necessary.

\section{Experimental protocol}

All operations were performed under sterile conditions under constant temperature of $37^{\circ} \mathrm{C}$. An abdominal incision was made; then the left renal artery and vein were occluded with a microvascular clamp for 30-minutes; after this process, the clamp was removed and the organ was allowed to reperfusion for 24 hours. Sham operations were performed in a similar fashion, except the vessels were not clamped. Surgical site was closed with 4-0 nylon.

\section{Samples collection}

The rats were euthanized by overdose of ketamine hydrochloride and xylazine hydrochloride injection (triple dose of anesthetic) at the end of the reperfusion period. The left kidney was harvested, and its adhering fatty tissue was carefully dissected. Then, $5 \mathrm{ml}$ of blood was also collected from inferior vena cava to assess oxidative stress.

\section{Preparation of kidney tissue homogenates}

The samples were washed three times in cold normal saline solution (0.9\%). Then, the tissues were homogenized in ice-cold Tris-HCl buffer solution within a homogenizer for $2 \mathrm{~min}$ at $11.200 \times \mathrm{g}$. The homogenate was centrifuged at $3500 \times \mathrm{g}\left(4^{\circ} \mathrm{C}\right)$ for $60 \mathrm{~min}$, and supernatant was obtained. Malondialdehyde (MDA) levels were studied in the homogenate and for a further extraction procedure, the supernatant was extracted in ethanol/ chloroform mixture (5/3 v/v). After a second centrifugation at $3500 \times \mathrm{g}$ for $20 \mathrm{~min}^{14}$.

\section{Biochemical analysis}

The MDA levels in kidney tissues and plasma were analyzed by a method based on the reaction with thiobarbituric acid at $95^{\circ} \mathrm{C}^{15}$. In the thiobarbituric acid test reaction, MDA or MDA-like substances and thiobarbituric acid react together to produce a pink pigment with an absorption maximum of $532 \mathrm{~nm}$. The results were expressed as $\mathrm{nmol} / \mathrm{g}$.

\section{Statistical analysis}

All data was statistically analyzed using BioEstat version 5.4. Data were expressed as mean \pm standard deviation. Analysis of variance (ANOVA) was used for statistical analysis of data among all groups. A value of $p<0.05$ was considered statistically significant.

\section{- Results}

All rats survived without major complications. The values of MDA of each group are shown in Table 1. 
Table 1 - Quantitative bacterial culture results.

\begin{tabular}{lcc}
\hline \multirow{2}{*}{ Groups } & \multicolumn{2}{c}{ MDA $(\mathrm{nmol} / \mathrm{g})$} \\
\cline { 2 - 3 } & Plasma & Kidney \\
\hline Sham & $0.15 \pm 0.04$ & $0.18 \pm 0.01$ \\
I/R & $0.58 \pm 0.13$ & $0.92 \pm 0.02$ \\
Per & $0.15 \pm 0.05$ & $0.23 \pm 0.02$ \\
Tramadol & $0.31 \pm 0.02$ & $0.42 \pm 0.03$ \\
Per+T & $0.19 \pm 0.07$ & $0.34 \pm 0.01$ \\
\hline
\end{tabular}

Data are expressed as means \pm SD.

Regarding plasma MDA levels (Figure $2)$, statistically significant difference of I/R was observed with the other groups $(p<0.01)$ and Tramadol with Sham, Per and Per+T groups ( $p$ $<0.05$ ).

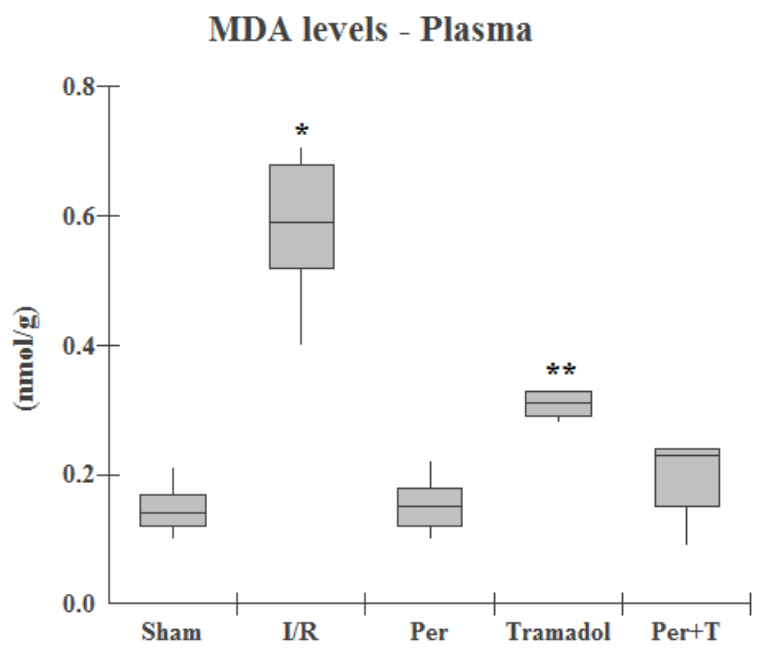

Figure 2 - Plasma levels of MDA between groups. ${ }^{*} p<0.01 /$ versus all groups; ${ }^{* *} p<0.05$ versus Sham, Per and Per+T groups. ANOVA (Tukey) test.

In kidney tissue, MDA showed a similar behavior when compared to plasma, a significant difference of $I / R$ with the other groups $(p<0.01)$ and Tramadol with the Sham, Per and Per $+T$ groups $(p<0.05)$ was also observed.

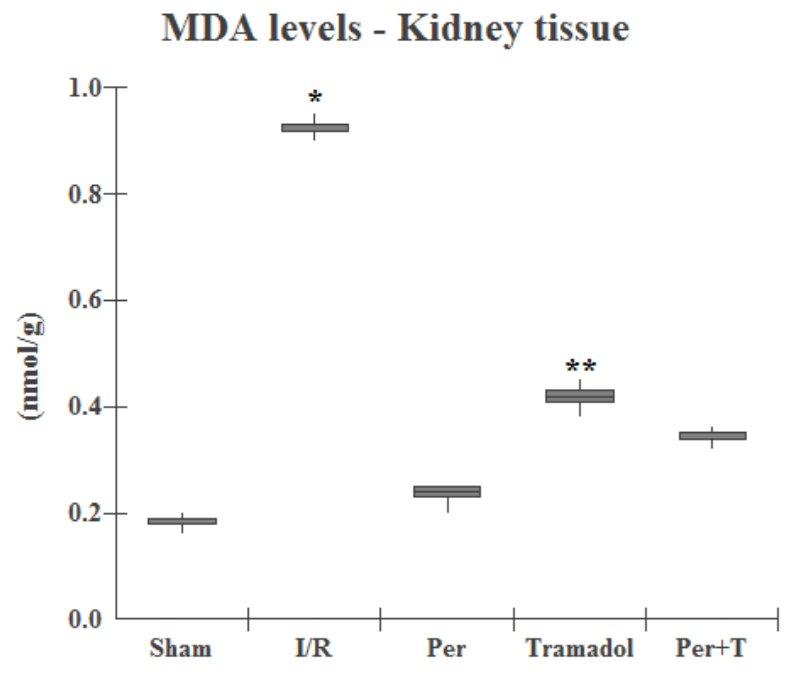

Figure 3 - MDA levels in kidney tissue between groups. ${ }^{*} p<0.01$ versus all groups; ${ }^{* *} p<0.05$ versus Sham, Per and Per+T groups. ANOVA (Tukey) test.

\section{Discussion}

This research demonstrated that remote ischemic perconditioning was more effective in reducing renal $I / R$ injury than administration of tramadol or association of both treatments.

In this study, I/R group showed significantly higher MDA levels in both serum and tissue analyses as compared to Sham group, demonstrating that experimental model was efficient, promoting lipid peroxidation and oxidative stress.

MDA levels were significantly higher in I/R group as compared to perconditioning, tramadol and Per+T, suggesting that they were efficient to maintain a higher antioxidant defense which allows further destruction of oxygen free radicals, reducing lipid peroxidation mediated by these reactive species released from the kidney tissue ${ }^{16}$.

The possible increase in antioxidant enzymes such as catalase, superoxide dismutase and glutathione peroxidase in these groups may be associated with reduced lipid peroxidation, which can play an important 
role on protective activity of ischemic perconditioning and tramadol ${ }^{10}$.

The mechanisms underlying the protective effects shown by ischemic conditioning remain unknown in the literature. However, it is suggested that initial mechanism of this process is the activation of neurohumoral pathway that activates defenses against the reperfusion injury of organs submitted to ischemia ${ }^{17}$.

Thus, application of ischemic conditioning in a remote organ can induce the release of humoral factors - such as adenosine, bradykinin and opioids - that under local innervation, cause activation of neural pathways that leads to renal protection. These effector signals activates specific cellular events, such as signaling cascades, known as RISK (Reperfusion Injury Salvage Kinase) and SAFE (Survivor Activating Factor Enhancement) that promote cell survival and increase tissue antioxidant defense at the organ submitted to ischemia ${ }^{18}$.

Furthermore, these results suggest that administration of tramadol, a centrally acting analgesic agent, may induce a renal protective effect against I/R oxidative injury. Many reports on literature describe beneficial use of this substance on experimental models such as transient forebrain ischemia $^{19}$, myocardial $^{16}$ and skeletal muscle $\mathrm{I} / \mathrm{R}^{12}$.

Tramadol is an opioid receptor agonist with less selectivity to $\mu$-receptor and weak affinity for $\mathrm{k}$ and $\delta$ receptors. The $\mathrm{k}$ opioid receptors play an inhibitory role on excitatory postsynaptic potentials possibly by closing $\mathrm{N}$-type calcium channels, decreasing the calcium input to the cell, while $\mu$ receptors are said to be involved in ischemic tolerance ${ }^{19}$.

Thereby, some evidences suggest that peripheral actions of tramadol involve increasing in antioxidant defenses. Mahmoud et al. ${ }^{20}$, showed the use of this substance reduced oxidative by means of glutathione peroxidase overexpression and decreasing in MDA formation. On the same way, Takhtfooladi et al. ${ }^{21}$ observed increasing in catalase and superoxide dismutase in skeletal muscle.

Although the reduction in oxidative parameters observed in tramadol group, its MDA levels was significantly higher than perconditioning group or $\mathrm{PER}+\mathrm{T}$, what can be possibly explained by subcutaneous administration, concentration of substance or protocol of treatment used, which was performed after the ischemic period.

Some reports associate intravenous administration of Tramadol with a protective effective against I/R in organs such as heart ${ }^{16}$, lung ${ }^{12}$ and skeletal muscle ${ }^{21}$. Therefore, intraperitoneal injection decreased cerebral ${ }^{19}$ and hepatic ${ }^{20} \mathrm{I} / \mathrm{R}$ injury in a rat model.

Further studies are necessary to evaluate the effects of tramadol on the renal function and histopathological aspects. Thus, alternative dosages and different protocols, such as intravenous, intraperitoneal or intramuscular administration of Tramadol, can be used in future researches.

\section{Conclusions}

Remote ischemic perconditioning was more effective reducing renal ischemiareperfusion injury than administration of tramadol or association of both treatments.

\section{- References}

1. Ávila MO, Rocha PN, Zanetta DM, Yu L, Burdmann Ede A. Water balance, acute kidney injury and mortality of intensive care unit patients. J Bras Nefrol. 2014 JulSep;36(3):379-88. doi: 10.5935/01012800.20140054.

2. Bellinger MA, Bean JS, Rader MA, HeinzTaheny KM, Nunes JS, Haas JV, Michael LF, Rekhter MD. Concordant changes of plasma and kidney microRNA in the early stages of acute kidney injury: time course in a mouse model ofbilateral renalischemia-reperfusion. PLoS One. 2014 Apr 2;9(4):e93297. doi: 10.1371/journal.pone.0093297.

3. Poljsak B, Šuput D, Milisav I. Achieving the 
balance between ROS and antioxidants: when to use the synthetic antioxidants. Oxid Med Cell Longev. 2013;2013:956792. doi: $10.1155 / 2013 / 956792$.

4. Fiorentini MR, Santos EB, Longo L, Kliemann LM, Koff WJ, Corso CO. Analysis of the effects of topical renal hypothermia on lung tissue after kidney ischemia and reperfusion in rats. Acta Cir Bras. 2015 Jul;30(7):445-51. doi: 10.1590/S0102-865020150070000001.

5. Brito MV, de Moreira RJ, Tavares ML, Carballo MC, Carneiro TX, dos Santos Ade A. Copaiba oil effect on urea and creatinine serum levels in rats submitted to kidney ischemia and reperfusion syndrome. Acta Cir Bras. 2005 May-Jun;20(3):243-6. doi: 10.1590/S010286502005000300009.

6. Percário S. Prevention of oxidative stress in renal ischemia-reperfusion syndrome in rats with nutritional antioxidant supplementation. Rev Nutr. 2010 Apr;23(2):259-67. doi: 10.1590/S141552732010000200009.

7. Rocha-Santos V, Figueira ER, Rocha-Filho JA, Coelho AM, Pinheiro RS, Bacchella T, Machado MC, D'Albuquerque LA. Pentoxifylline enhances the protective effects of hypertonic saline solution on liver ischemia reperfusion injury through inhibition of oxidative stress. Hepatobiliary Pancreat Dis Int. 2015 Apr;14(2):194-200. doi: 10.1016/S1499-3872(15)60348-4.

8. Yamaki VN, Gonçalves TB, Coelho JV, Pontes RV, Costa FL, Brito MV. Protective effect of remote ischemic per-conditioning in the ischemia and reperfusion-induce renal injury in rats. Rev Col Bras Cir. 2012 Dec;39(6):529-33. doi: 10.1590/S010069912012000600014.

9. Yetgin T, Manintveld OC, Boersma E, Kappetein AP, van Geuns RJ, Zijlstra F. Remote ischemic conditioning in percutaneous coronary intervention and coronary artery bypass grafting. Circ J. 2012;76(10):2392404. doi: 10.1253/circj.CJ-12-0518.

10. Costa FL, Yamaki VN, Gonçalves TB, Coelho JV, Percário S, Brito MV. Combined remote ischemic perconditioning and local postconditioning on liver ischemiareperfusion injury. J Surg Res. 2014 Nov;192(1):98-102. doi: 10.1016/j. jss.2014.05.046.

11. Headrick JP, Pepe S, Peart JN. Non-analgesic effects of opioids: cardiovascular effects of opioids and their receptor systems. Curr Pharm Des. 2012;18(37):6090-100. doi: 10.2174/138161212803582360.

12. Takhtfooladi MA, Jahanshahi A, Sotoudeh A, Jahanshahi G, Takhtfooladi HA, Aslani K. Effect of tramadol on lung injury induced by skeletal muscle ischemia-reperfusion: an experimental study. J Bras Pneumol. 2013 Jun-Aug;39(4):434-9. doi: 10.1590/S180637132013000400006.

13. Ahmed MA, Kurkar A. Effects of opioid (tramadol) treatment on testicular functions in adult male rats: the role of nitric oxide and oxidative stress. Clin Exp Pharmacol Physiol. 2014 Apr;41(4):317-23. doi: 10.1111/14401681.12213.

14. Parlaktas BS, Atilgan D, Gencten Y, Akbas A, Markoc F, Erdemir F, Ozyurt H, Uluocak N. The effects of carvedilol on ischemia-reperfusion injury in the rat testis. Int Braz J Urol. 2014 Jan-Feb;40(1):109-17. doi: 10.1590/S16775538.IBJU.2014.01.16.

15. Wasowicz W, Nève J, Peretz A. Optimized steps in fluorometric determination of thiobarbituric acid-reactive substances in serum: importance of extraction $\mathrm{pH}$ and influence of sample preservation and storage. Clin Chem. 1993 Dec;39(12):25226. PMID: 8252725.

16. Bilir A, Erkasap N, Koken T, Gulec S, Kaygisiz Z, Tanriverdi B, Kurt I. Effects of tramadol on myocardial ischemia reperfusion injury. Scand Cardiovasc J. 2007;41:242-7. doi: 10.1080/14017430701227747

17. Costa FLS, Teixeira RKC, Yamaki VN, Valente $A L$, Silva AMF, Brito MVH, Percário S. Remote ischemic conditioning temporarily improves antioxidant defense. J Surg Res. 2016 Jan;200(1):105-9. doi: 10.1016/j. jss.2015.07.031.

18. Szijártó A, Czigány Z, Turóczi Z, Harsányi L. Remote ischemic perconditioning - a simple, low-risk method to decrease ischemic reperfusion injury: models, protocols and mechanistic background. A review. J Surg Res. 2012;178(2):797-806. doi: 10.1016/j. jss.2012.06.067.

19. Nagakannan P, Shivasharan BD, Thippeswamy BS, Veerapur VP. Effect of tramadol on behavioural alterations and lipid peroxidation after transient forebrain ischemia in rats. Toxicol Mech Methods. 2012;22:674-8. doi: 
10.3109/15376516.2012.716092.

20. Mahmoud FM, Gamal S, Shaheen MA, ElFayoum HM. The effects of tramadol on hepatic ischemia/reperfusion injury in rats. Indian J Pharmacol. 2016 MayJun;48(3):275-80. doi:
10.4103/02537613.182882.

21. Takhtfooladi HA, Takhtfooladi MA, AsI PKHA, Mobarakeh SZMN. Influence of tramadol on ischemia-reperfusion injury of rats' skeletal muscle. Int J Surg. 2014;12:963-8. doi: 10.1016/j.ijsu.2014.07.015.

\section{Correspondence:}

Rubens Fernando Gonçalves Ribeiro Júnior

Avenida Marquês de Herval, 1823

66087-320 Belém - PA Brasil

Tel.: (55 91)98133-7502

rubensfernandojr@gmail.com

Received: Nov 18, 2016

Review: Jan 12, 2017

Accepted: Feb 15, 2017
Conflict of interest: none

Financial source: PIBIC-UEPA
${ }^{1}$ Research performed at Laboratory of Experimental Surgery, Universidade Estadual do Pará (UEPA), Belem-PA, Brazil. 